MATEC Web of Conferences 13, 02024 (2014)

DOI: $10.1051 /$ matecconf/ 20141302024

(C) Owned by the authors, published by EDP Sciences, 2014

\title{
Factors affecting fill removal from horizontal well during colied tubing cleanout operation
}

\author{
William K. Pao a and Javed A. Khan \\ Mechanical Engineering Department, Universiti Teknologi PETRONAS, 31750 Tronoh, Perak, \\ MALAYSIA
}

\begin{abstract}
Coiled Tubing (CT) is extensively used in oil industry to clean the wellbore to increase the productivity of oil/gas well by removing the fill/sand downhole. Well cleanup operation for low bottom hole pressure is problematic and common cleanout fluids are not effective as a circulation fluid due to severe pressure losses and low suspension capability. The use of foam as cleaning agent has become more popular due to its low density and high viscosity. The objective of this paper is to investigate the factor effecting on fill concentration and pressure loss during horizontal wellbore cleanup operation at different CT/Annulus diameter ratios using Herschel Buckley viscosity model. Results showed that foam quality has the significantly high effect on fill concentration as compared to foam velocity. It is noticed that diameter ratio has high effect on particle removal when foam quality is $70 \%$. Surprisingly, it is found that the effect of diameter ratio on fill concentration decreases when foam quality is $90 \%$.
\end{abstract}

\section{Introduction}

Fill (sand and fine) material left in the cased annulus reduces the production of wellbore. Therefore ,well cleaning operation is required to enhance the oil/gas production. Currently, fill removal is the largest CT application with approximately $50 \%$ of all CT operations industry wide [1]. Coil Tubing has two circulation modes to remove solid particles, namely the forward and reverse circulation modes. In the forward circulation mode, Cleaning fluid is pumped in the tubing and mixture of fill and foam is circulated back through cased annulus. On the other hand, reverse circulation is carried out by injecting fluid from cased annulus and circulated back through coiled tubing. Present study is focused on the forward circulation flow of the cleaning fluid. Solid particles transport is problematic in horizontal wellbore [2]. In this situation, fill particles drop down the lower side of annulus and form a solid bed. In practice, the velocity of circulation fluid in the annulus is kept greater than the settling velocity of the particle. This is to ensure that the circulation fluid has higher buoyancy force than the gravity force of solid particles. Selection of fluid is the important factor in designing the cleanout operations [3]. To overcome the problem, study is forwarded to analyze the fill removal with foam along horizontal well.

\footnotetext{
${ }^{a}$ Corresponding author: William.Paokings@petronas.com.my
} 


\section{Literature review}

The foam is generated by mixing in a gas phase with a foaming agent and a base fluid. Water and oil are the most typical kind of base fluids. The foaming agent ( 0.5 to $1 \%$ by volume) is a surfactant. It is used to lower the surface tension between the gas and the base fluid [4]. Saintpere et al. [5] reported that foam rehology follow the Herschel Bulkley viscosity model.

Herzhaft et al. [6] experimentally studied that solid transport efficiency increases with high quality of foam. Li and Kuru [7] incorporated a model for hydraulic calculations of cutting transport with foam during horizontal wellbore drilling operation. They found a relation for the critical velocity of foam to transport the drill cuttings. They analyzed that cuttings efficiency increases at higher foam flow rate. Li and Kuru [8] concluded that critical velocity of foam has no effect of temperature variation between $30^{\circ} \mathrm{C}$ and $100^{\circ} \mathrm{C}$. Loureno et al. [9] also verified experimentally that rehology of foam has no influence of change in temperature.

In the past, drilling cuttings transport with foams has been studied along the horizontal wellbore, study has forwarded to understand the fill transport with foam along horizontal wellbore during coiled tubing cleanup operation. Recently, Khan and Pao $[10,11]$ reported that well cleaning can be achieved with lower quality of foam as long as its circulating velocity is high i.e. $6 \mathrm{ft} / \mathrm{sec}$. They also observed that sand settled down at bottom of annulus and form continues bed when the annular velocity is less than $5 \mathrm{ft} / \mathrm{sec}$. They concluded that fill concentration in the annulus is mostly dictated by foam quality rather than its velocity. They also found that pressure loss increases with the increase in the foam quality.

\section{Methodology}

In the present study, ANSYS-CFX-14 is used to analyze the fill removal from horizontal wellbore using foam as a cleaning fluid. Bailey et al. [12] also used this method to investigate the pressure gradient of non Newtonian slurry composed of gel and sand at reel to injector section of coiled tubing. Similar approach has been used by Bilgesu et al. [13] to investigate the cutting transport efficiencies in vertical well. In the present study, the flow is assumed to be in pseudo-steady state condition. Following is the Herschel-Bulkely rheological relation of foam.

$$
\tau=\tau_{0}+K \gamma^{n}
$$

where, $\tau$ is the shear stress, $\tau_{o}$ is the yield stress, $K$ is the consistency index, $\gamma$ is the shear rate and $n$ is the power index for non-Newtonian fluid. Herschel-Bulkely viscosity model parameters for water base foam was analyzed by Miska et al. [14] as shown in Table 1, and their values are assumed valid in the present study.

Table 1: Rheological Model Parameters

\begin{tabular}{|c|c|c|c|c|}
\hline \multirow{2}{*}{$\begin{array}{l}\text { Liquid } \\
\text { Phase }\end{array}$} & \multirow{2}{*}{ Parameters } & \multicolumn{3}{|c|}{ Quality (\%) } \\
\hline & & 70 & 80 & 90 \\
\hline \multirow{3}{*}{$\begin{array}{c}\text { Water } \\
\text { based } \\
\text { foam } \\
\text { properties }\end{array}$} & $\eta$ & 0.53 & 0.45 & 0.42 \\
\hline & $\tau_{0}(\mathrm{~Pa})$ & 0.0004 & 0.000009 & 0.001379 \\
\hline & $K($ Pa.s $)$ & 0.6894 & 1.999 & 2.8268 \\
\hline
\end{tabular}

The foam velocities are applied at annulus inlet. The rate of penetration of tubing inside the fill is taken $60 \mathrm{ft} / \mathrm{hr}$. There is a uniform injection of fill particles at annulus inlet. Injection flow rate of solid particles is calculated using Equation 2. Boundary conditions are applied on the surface of domain to define the foam and solid phases as shown in Figure 1.

$$
Q=\rho V A \text {, }
$$


Where, $Q$ is the mass flow rate, $\rho$ is the density of fill, $V$ is the velocity of particle and $A$ is the area of annulus.

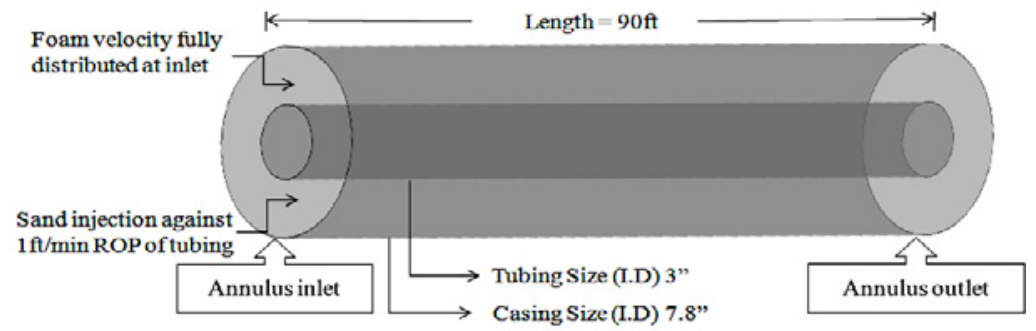

Figure 1: Schematic well diagram

Particle transport multiphase model was chosen to calculate the mass fraction of the fill particles along the annulus. All the particles were tracked, starting from the area of injection until the exit area of fill particle throughout continues foam phase. The track of particle was carried out by formulating a set of regular equations in time for each fill particle.

The displacement of the particle is calculated using forward Euler integration of each particle velocity over time step as shown in Equation 3 and velocity of particle is calculated using Equation 4.

$$
\begin{aligned}
& x_{i}^{n}=x_{i}^{o}+v_{p i}^{o} \delta t, \\
& v_{p}=x_{f}+\left(v_{p}^{o}-v_{f}\right) \exp \left(-\frac{\delta t}{\tau}\right)+\tau F_{\text {all }}\left(1-\exp \left(-\frac{\delta t}{\tau}\right)\right),
\end{aligned}
$$

where, $x$ is the particle displacement, $n$ is the new position of sand particle, $O$ is the old position of particle, $V_{P}$ is the particle velocity and $\delta t$ is the time step, $v_{f}$ is the foam velocity, $\tau_{\text {is }}$ the shear stress and $F_{\text {all }}$ is the sum of all forces. The momentum of solid particles is calculated using Equation 5.

$$
m_{p} \frac{d U p}{d t}=F D+F B+F P+F R
$$

where, $m_{p}$ is the mass of the solid particle, $d U p / d t$ is the particle velocity and $F D$ is the drag forces acting on the particle, $F B$ is the bouncy force due to gravity, $F P$ is the pressure gradient force and $F R$ is the force due to domain rotation. The explanation for above mentioned forces are omitted but its detail description can be found in the ANSYS-CFX version 14.0-Solver Theory Guide [15]. The interaction between these forces affects the solid particle transport during fluid circulation.

\section{Result and discussion}

In the previous study Khan and Pao [10], verified a numerical model with the experimental study which was carried out by Chen et al. [16]. It was noticed that the decrease in particles concentration was almost matching with the experimental study. It has been verified that the numerical model is set for the parametric study of fill transport with foam during coil tubing cleanup operation. Numerical analysis was carried out by using following parameters as shown in Table 2.

Table 2: Parameter for simulation

\begin{tabular}{|c|c|c|c|}
\hline $\begin{array}{l}\text { Foam quality } \\
(\%)\end{array}$ & $\begin{array}{l}\text { Foam velocity } \\
(\mathrm{ft} / \mathrm{sec})\end{array}$ & $\begin{array}{l}\text { Fill diameter } \\
(\mathrm{mm})\end{array}$ & $\begin{array}{l}\text { Diameter ratio } \\
(\mathrm{CT} / \text { Annulus })\end{array}$ \\
\hline 70 & $3,4,5,6$ & $0.5,1,2,3$ & $0.35,0.4,0.45,0.5$ \\
\hline 80 & $3,4,5,6$ & $0.5,1,2,3$ & $0.35,0.4,0.45,0.5$ \\
\hline 90 & $3,4,5,6$ & $0.5,1,2,3$ & $0.35,0.4,0.45,0.5$ \\
\hline
\end{tabular}


Effect of different qualities on fill concentration of varying size of particles: In all of the studies, a decreasing trend for the fill concentration is noticed as fluid quality increases for all CT/Annulus diameter ratio. The relationship between the concentration of the fill and the quality of the foam at each diameter ratio and constant foam velocity of $6 \mathrm{ft} / \mathrm{sec}$ is presented in Figure 2 (a) and (b). It can be observed that there is a significant decrease in fill concentration when quality of foam is less than $80 \%$. Rate of decreases in the fill concentration reduces when foam quality increases from 80 to $90 \%$.

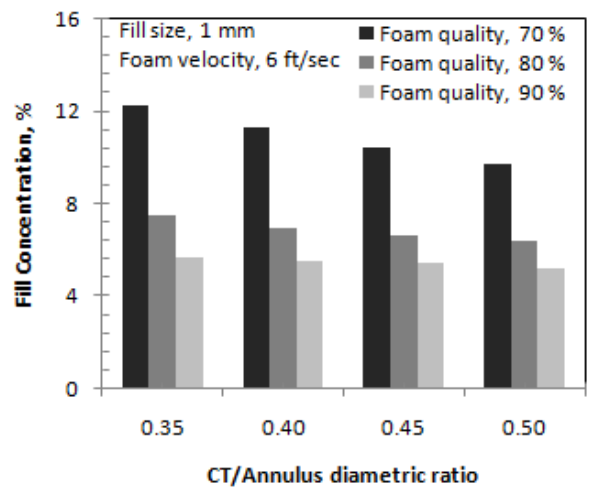

(a)

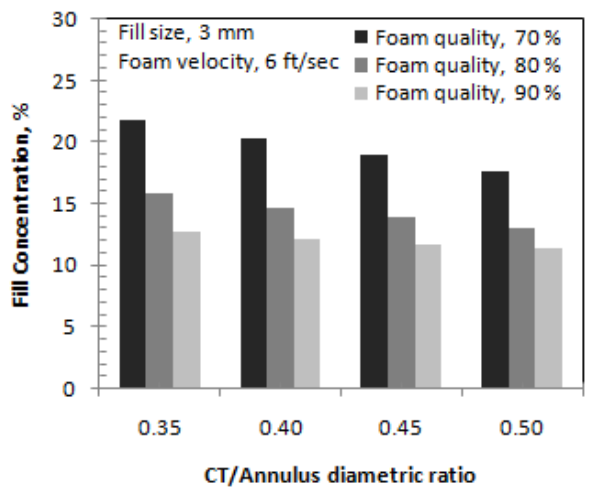

(b)

Figure 2: Effect of foam quality on the fill concentration of small and large size of particles at different $\mathrm{CT} /$ Annulus diameter ratios (a) Effect of quality when particle size is $1 \mathrm{~mm}$ (b) Effect of quality when particle size is $3 \mathrm{~mm}$

Effect of different velocities on fill concentration of varying size of particles: In all of the studies, a decreasing trend for the fill concentration is noticed as fluid velocity increases for all of the $\mathrm{CT} /$ Annulus diameter ratios and fill sizes. The relationship between the concentration of different fill sizes and velocities of the foam at each diameter ratio is presented in Figure 3 (a) and (b). It is found that there is a significant decrease in the fill concentration of small size particles and large size particles when foam velocity increases from 3-5 ft/sec. As, the foam velocity increases from 5-6 $\mathrm{ft} / \mathrm{sec}$ than there is insignificant decrease in the fill concentration at small size of fill particles and a considerable decreases in the concentration of large particles.

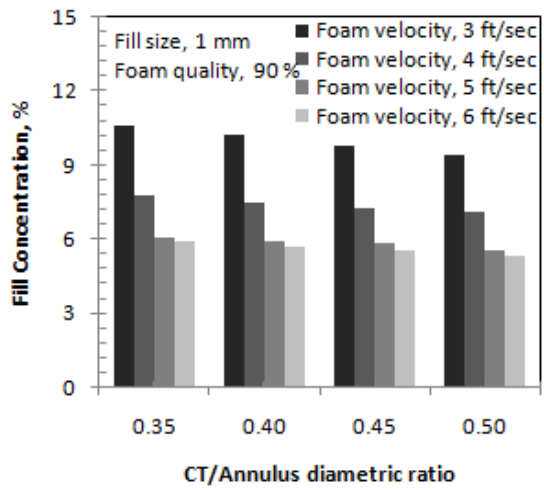

(a)

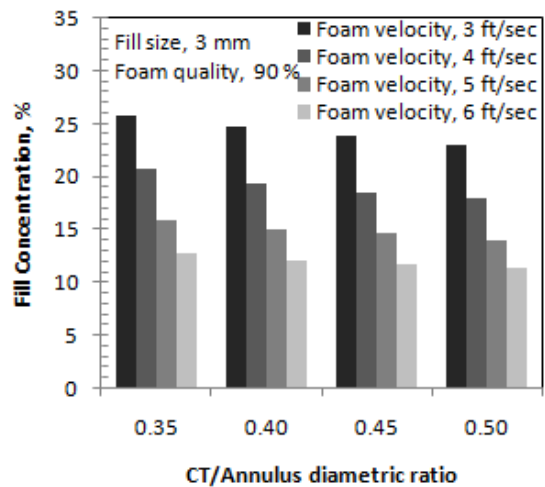

(b)

Figure 3: Effect of foam velocity on the fill concentration of small and large size of particles at different $\mathrm{CT} /$ Annulus diameter ratios (a) Effect of velocity when particle size is $1 \mathrm{~mm}$ (b) Effect of velocity when particle size is $3 \mathrm{~mm}$ 


\section{Conclusion}

Foam has the higher efficiency of solid particles transport because its structure does not allow the fallback of solids, even under low circulation velocities. A decreasing trend for the fill concentration is noticed as fluid quality and velocity increases for all of the CT/Annulus diameter ratios. Fill removal has better performance with foam of low quality at annular velocity of $6 \mathrm{ft} / \mathrm{sec}$. Present study showed that foam quality affect more on the fill concentration than the velocity of foam and diameter ratio.

\section{Acknowledgment}

The authors would like to acknowledge the financial assistant by Universiti Teknologi PETRONAS under the Graduate Assistance Scheme.

\section{References}

[1] Li J, Green T (2011) Coiled Tubing Sand Clean Outs Utilizing BHA Technology and Simulation Software in Demanding Wellbore Geometries. SPE 149051.

[2] Li J, Luft B (2006) Fills Cleanout with Coiled Tubing in the Reverse Circulation Mode. Paper IADC/SPE 102661.

[3] Walton IC (1995) Computer Simulator of Coiled Tubing Wellbore Cleanouts in Deviated Wells Recommends Optimum Pump Rate and Fluid Viscosity. Paper SPE 29291.

[4] Li S, Li Z, Lin R and Li B (2010) Modeling of sand cleanout with foam fluid for vertical well. Paper SPE 120449.

[5] Saintpere S, Marcillat Y,Bruni F, and Toure A (2000) Hole cleaning capabilities of drilling foams compared to conventional fluids. Paper SPE 63049.

[6] Herzhaft B, Toure A, Bruni F and Saintpers S (2000) Aqueous foams for underbalanced drilling: The question of solids. Paper SPE 62898.

[7] Li Y and Kuru E (2003) Numerical modeling of solid particles transport with foam in horizontal wells. Journal of Canadian Petroleum Technology, Vol. 42, No.10.

[8] Li Y and Kuru E (2004) Prediction of critical foam velocity for effective cutting transport in horizontal wells. Paper SPE 89324.

[9] Lourence A, Miska S, Reed T, Pickell M and Takah N (2003) Study of the effects of pressure and temperature on the rehelogy of drilling foams and frictional pressure losses. Paper SPE 84175.

[10] Khan JA and Pao WS (2013) Fill Removal with foam in horizontal well cleaning in coiled tubing. Research Journal of Applied Sciences, Engineering and Technology 6(14): 2655-2661, 2013.

[11] Khan JA and Pao WS (2013) Effect of different qualities of foam on fill particle transport in horizontal well cleanup operation using coiled tubing. Accepted in International Manufacturing Engineering Conference in Kuantan, Pahang, Malaysia. Conference date July 1-3.

[12] Bailey M, Blanco I and Rosine R (2006) Reel to injector fluid flow analysis using CFD software. Paper SPE 100141.

[13] Bilgesu HI, Ali MW, Aminian K and Ameri S (2002) Computational Fluid Dynamics (CFD) as a tool to study cutting transport in wellbores. Paper SPE 78716.

[14] Miska SZ, Reed T and Takach N (2003) Cutting transport with foam in horizontal \& highly inclined wellbores. Paper SPE/IADC 79856.

[15] ANSYS CFX version 14.0 (2011) Solver Theory Guide - Particle Transport Theory, page 241246.

[16] Chen Z, Ahmed RM, Miska SZ, Takach NE, M Yu and Pickell MB (2007) Experimental study on cuttings transport with foam under simulated horizontal downhole conditions. Paper SPE 99201. 